ORIGINAL ARTICLE

\title{
Influence of static balances level on competitive performance indicators of athletes 17-21 years old in beach volleyball
}

\author{
Oleksandr Solovey ${ }^{1 \mathrm{ABCDE}}$, Valeriy Hunchenko ${ }^{1 \mathrm{ABCDE}}$, Dmytro Solovey ${ }^{1 \mathrm{BCDE}}, K$ rzysztof Wnorowski ${ }^{2 \mathrm{DE}}$ \\ ${ }^{1}$ Prydniprovska State Academy of Physical Culture and Sports, Ukraine \\ ${ }^{2}$ Gdansk University of Physical Education and Sport, Poland \\ Contribution of authors: \\ A - Research design; B - Data collection; C - Statistical analysis; D - Preparation of the manuscript; E-Funds Collection
}

\begin{abstract}
Purpose: $\quad$ To determine the influence of the level of static balance on the competitive activity of athletes aged 17-21 in beach volleyball.

Material: $\quad$ The study involved athletes aged 17-21 years, who play beach volleyball in the Kherson region. The research was focused on the main indicators: the total number of serves, passes, tactical strikes, blocks, and how the development of static balance affects the level of their performance.

Results: $\quad$ Acrobatic exercises in training activities for special physical training positively contributed to the increase in the samples of Bondarevsky $(p<0.05)$, Romberg $(p<0.05)$ and Yarotsky $(p<0.05)$. Samples with different nature of the work performed reflect different aspects of static equilibrium: samples of Bondarevsky and Yarotsky most reflect the nature of the work performed during the competitive activities of athletes; Romberg's test only partially corresponds to these indicators.

Conclusions: The proposed methodological approach significantly affects the performance of competitive activities and is directly related to the quality of tactical strikes, high-level performance in defense and the number of serves. The results of the study indicate the difference in samples with different nature of the work. Overstrain of the vestibular centers can negatively affect the quality of tactical strikes in the attack and blocking.

Keywords: beach volleyball, competitive activity, efficiency, vestibular stability, correlation coefficient, static balance.
\end{abstract}

\section{Introduction}

The stage of preparation for the highest sports skills is one of the key steps in the preparation process of athletes to the main competitions in the chosen kind of sport. The task of the stage is reaching the maximum results in all kinds of sports. The main purpose of the stage is to ensure the rapid flow of adaptation processes through the use of tools that can cause them [1]. The conditions of training should correspond to the following: the period of the most intensive training loads should coincide with the period of maximum propensity of the athlete to achieve the highest results [1]. Physical training of athletes is the basis of the process of sports improvement [1-3].

The leading physical qualities of beach volleyball athletes are: strength, and on its basis - speed-power and speed qualities and agility [4-8]. Agility is based on coordination abilities, which largely depend on the stability of vestibular reactions. The feeling of the position of the body and individual biolinks in space, including movement, refers to the properties of the central nervous system. This ability is divided into: static balance (the ability to maintain the stability of the pose); dynamic balance (the ability to maintain balance during the movements of the whole body) and the most important and significant quality - vestibular (statokinetic) stability (the ability to accurately perform individual or global movements during vestibular stimuli) $[9,10]$.

Statokinetic stability depends on static and dynamic o Oleksandr Solovey, Valeriy Hunchenko, Dmytro Solovey,

Krzysztof Wnorowski, 2020

doi:10.15561/20755279.2020.0605 balance and stability of vestibular reactions [11, 12]. Game sports are accompanied by constant changes in body position, jumping, falling, accelerating and rapid transitions from one stage to another [13-15].

In various sports, statokinetic stability plays a significant role in the manifestation of coordination skills and agility. According to Platonov [3] coordination abilities are manifested in predetermined conditions of complex movements. Agility is based on coordination abilities and is manifested in unpredictable conditions, namely the influence of external or internal factors on the movements of the athlete. External factors may include weather conditions (sun, wind, loose soil), variable trajectory of the ball, opposition of the opponent, to internal - deviations in the initial positions of the body due to changes in external factors and correction of body movement taking into account afferent innervation body. All these factors are integral and pronounced components of competitive activity in beach volleyball. In view of this, in relation to beach volleyball, it is advisable to use the term - agility. Therefore, the study of one of the components of vestibular stability, as a component of agility, should be of interest to scientists involved in the problem of successful human motor activity. One of the areas of this issue is training in sports, and in particular in beach volleyball, where it is extremely important. However, the analysis of scientific and methodological literature shows that at present there are only a few pieces of information on improving the process of physical training of beach volleyball athletes by improving psychomotor qualities. 
In volleyball, this problem was solved by Kozina et al. [16] and Zamporri et al. [17], using exercises to develop static balance. Horchanyuk [18, 19] emphasizes the need to use models of jumps and movements to improve the process of sports training in sports training. Lysyansky et al. [20] pay attention to the control over the process of sports training in beach volleyball and its adjustment on this basis. Kostyukov [21, 22], Hemberg and Papaheorhiou [23], consider didactic and methodological approaches to the training process, improving the technical and tactical component of training of athletes, give examples of physical, technical and tactical training of leading athletes in beach volleyball and provide scientific advice on improvement of the specified work due to optimization of process of trainings and use of the advanced practical experience.

Lin [24] and Gunchenko [25] state that high-quality performance of various, in particular power serve, is a significant reserve for improving the effectiveness of competitive activities, emphasize that in the competitive activities of volleyball players there is both static and dynamic balance, which actualizes the adoption of appropriate tactics in practice.

Giatcis [26] came to the conclusion that the latest changes in the rules of the beach volleyball game (the size of the court) have led to an increase in the spectacle of matches, an increase in the number of games, where the result is determined in 3 sets. This determines their uncompromisingness and unpredictability of the result. It also increases the total number of draws held in the game, which puts forward increased requirements for the physical fitness of athletes.

Drikos et al. [27] derive the coefficients of efficiency of the serve (the ratio of lost serves to the won) and the coefficient of the efficiency of the attack (the ratio of the won blows to the lost and blocked).

Portuguese scientists Araújo et al. [28] note that competitive activities in men's volleyball are characterized by constant adaptation to the tactics of the players as attack and defense. The relationship between blocking and strikes in an attack in elite men's beach volleyball is given. The coefficients of effectiveness of a particular type of blocking depending on the attack zone were calculated, these trends must be taken into account in the training process.

Platonov [3] argues that the physical training is a key component for achieving results in competitive activities. Tymoschenko [5] emphasizes the development of maximum force accuracy. Solovey and Hunchenko [4] found that increasing the number and quality of stable power supplies in the jump in beach volleyball and offensive strikes makes it impossible to predict the development of offensive actions. This precludes the construction of appropriate defensive actions, which significantly increases the effectiveness of tactical offensive strikes of a bypass nature and the effectiveness of competitive activities in general. The increase in quantitative indicators in actions that require maximum explosive force directly depends on the physical fitness of athletes. Further sports improvement involves increasing the efficiency of the training process through new areas and strategies to improve the process.

Most scientists suggest increasing the intensity and volume of load in the process of sports improvement. However, this direction has its limits, which are determined by the objective regularity of development and formation of sportsmanship. In this regard, it is essential to find alternative sources to improve the process of sports training.

Platonov [1, 3], Kozina [16] emphasize the need for individualization and differentiation of means and methods of sports training, as well as the development of new approaches to building a training process in preparation for higher achievements.

Competitive activity determines the features of the sport. Beach volleyball, like other sports, is a complex coordination sport [3, 13, 29].

The effectiveness of certain elements of the technique of the game during the competition indicates the level of game readiness of athletes. This determines their competitiveness and achievements during the competition. Analysis of the strengths and weaknesses of the training of athletes allows us to conclude which technical components and physical shortcomings require increased impact and determine the leading physical qualities in beach volleyball.

Thus, Doroshenko [30] focuses on the processes of management of technical and tactical activities and sports training on the basis of control data; Balasas et al. [31] prove that 12 weeks of fitness training in beach volleyball increase the level of development of strength and endurance of leg muscles, increase the effectiveness of the jump by $11.6 \%$, including on hard surfaces; Kostiukevich [29] suggests using exercises of increased coordination difficulty during the training process in sports games. This will provide a significant level of variability in technology. Shankulov et al. [32] show that the greatest number of loads on the development of coordination, agility and vestibular stability should be planned in the preparatory period. This will help to achieve the best state of sports readiness of the team before the start of the competitive season. At the end of the preparatory period, the amount of load is purposefully reduced in order to maintain optimal functional and physical fitness of athletes.

The analysis of the strengths and weaknesses of the training of athletes allows us to draw conclusions about which technical components and physical shortcomings need increased impact and determine the leading physical qualities in volleyball.

Tili and Giatcis [33] analyzed the growth rates of the winners of women's games under the aegis of the FIVB depending on the specialization and size of the court. Silva et al. [34] carried out research on analytical materials used in classical volleyball. These materials were comparative and prognostic in nature. The influence of the conducted methods on the performance and efficiency of games, as well as computer programs used were investigated. Medeiros et al. [35] state a gradual 
transition from descriptive to comparative and prognostic analysis of beach volleyball matches. Also they state the lack of analytical studies of the impact of physical components of sports fitness on technical and tactical level and the level of resistance to the performance of competitive activities in general. Coliago [36] in his study developed the structure and content of sports training in the annual cycle of beach volleyball athletes. He offered an effective ratio of training loads, versatility and efficiency of performance of technical receptions that promoted increase of efficiency of performance of separate game elements. Castro et al. [37] investigated the dependence of the effectiveness of a counterattack in classical volleyball depending on its speed, power, and the number of blocking opposing players. Papadimitriu et al. [38] analyzed the effectiveness of attacking actions of world-class volleyball teams depending on the quality of actions of the player performing the passing.

The social status of beach volleyball is constantly growing. The problems of improving the training process of beach volleyball athletes in scientific publications at the expense of alternative directions and strategies for the development of the sport are insufficiently covered. This determined the relevance of our study.

Hypothesis. It is assumed that the static balance and stability of vestibular reactions have a significant impact on the efficiency and effectiveness of certain technical elements during the competition, and on the outcome of competitive activities in beach volleyball.

The purpose of the study is to determine the influence of the level of static balance on the indicators of competitive activity of athletes aged 17-21 in beach volleyball.

\section{Material and Methods.}

Participants. This study involved beach volleyball athletes aged 17-21 who play beach volleyball in the Kherson region (Ukraine). During the experiment, an experimental group of 20 young men was created. All study participants gave written consent to participate in the experiment.

Research Design.

The basis for the study were: Kherson State University (Kherson, Ukraine), Children's and Youth Sports School № 6 (Kherson, Ukraine). Training participants were trained 6 times a week. The training process lasted from December 2018 to April 2019 and was allocated 704 hours (32 hours per week) during the training period.

The main task of microcycles was to ensure the adaptation in the body of athletes, solving the main tasks of physical and technical and tactical training. During the work, special attention was paid to special physical training with an emphasis on acrobatic training. Two blocks of acrobatic exercises were developed, which were used in the preparatory and main part of each of the training sessions of complex orientation and totaled 20 minutes of training work. In the exercise blocks, rollovers, a "wheel" and handstands were used. Both blocks of exercises were used in each of the classes. The total amount of work for all types of training was characterized as significant, and the load was $70-80 \%$ of the maximum possible.

At the end of the preparatory period, the level of ability to static balance was tested using a number of tests, such as the Romberg test, the Yarotsky's test and the Bondarevsky test. Romberg's test [39] was as follows - the time during which the subject maintained balance was measured; Modified Yarotsky's test (MYT) [12] balance retention time was measured; Bondarevsky's test [11] - the number of attempts for which the subject could stand in balance for 1 minute was counted.

Subsequently, a video of games in which athletes participated in the experiment (one game of each participant) at the Games of the Championship of Ukraine (U21) and the open championship of Kherson State University in beach volleyball (Kherson, Ukraine) was recorded. The method of expert evaluation of athletes' actions based on videos was used. Five experts (coaches with more than 20 years of experience) were involved. The number and level of performance of certain elements of beach volleyball technique in competitive conditions were analyzed. The level of performance provided for the division of elements of technology into three stages: high level, medium and low. The high level of performance of the element of technology provided: the ability to perform the following technical actions of his team, winning a point, or extremely difficult further technical actions of the opposing team. Medium level - made it difficult for the players of his team to carry out further technical actions or significantly complicated the actions for the opposing team. Performing a technical technique at a low level resulted in a point loss, did not complicate the further actions of the players of the opposing team, or significantly complicated the performance of further technical actions of his team.

Statistical analysis. In the process of analysis average, average error, correlation and variation coefficients were calculated. To determine the consistency of experts' opinions on each of the technical actions, a coefficient of variation was calculated, and a correlation analysis was calculated to establish the relationship between the indicators. Microsoft Excel 2007 was used to calculate the correlation coefficient of tests for static balance with quantitative and qualitative indicators of performance of elements of game technique in competitive conditions. The result was significant at $\mathrm{p}<0.05$.

\section{Results}

The application of a methodical approach to the planning of training sessions on special physical training based on the use of acrobatic training, as well as ensuring the adaptation of athletes in beach volleyball, positively contributed to the increase in the samples of Bondarevsky $(\mathrm{p}<0.05)$, Romberg $(\mathrm{p}<0,05)$ and Yarotsky $(\mathrm{p}<0.05)$ (Table 1).

Purposeful influence on the main parameters of the arsenal of technical and tactical actions allowed increasing the effectiveness of attacking actions of athletes in beach volleyball. There is a noticeable tendency to increase the number of: medium and low levels $(p<0.05)$ and medium 
levels of reception $(\mathrm{p}<0.05)$, high and medium levels ( $\mathrm{p}$ $<0.05)$; high-level tactical strikes $(\mathrm{p}<0.05)$; high-level power strikes $(\mathrm{p}<0.05)$ and high level of defense $(\mathrm{p}$ $<0.05$ ); high-level blockages ( $\mathrm{p}<0.05)$.

The consistency of experts' opinions on each of the technical actions was quite high. Coefficients of variation range from $8.15 \%$ to $12.47 \%$. Since $V \leq 15 \%$, the opinions are consistent, the set is homogeneous and the results can be trusted.

The obtained correlation coefficients indicate the presence of an inverse relationship at the average level of the quantitative indicator of the performed feeds with the Bondarevsky's test (Table 2).

That is, with increasing test rate (deterioration) the number of serves decreases. No significant dependencies were detected with the performance of the serve at a high level. With the performance of the mid-level serve, there is an inverse relationship between the middle level and the low-level feed. As the test rate increases (deterioration), the number of serves in general and performed at medium and low levels decreases.

With the technical action of the serve in the test there is a complex relationship. With the implementation of the reception of the serve at a high level there is a weak inverse relationship, with the implementation of the medium level, the average direct dependence. As the test deteriorates, the number of medium-level serves increases and the high level decreases slightly.

Bondarevsky's test with the pass for the attack has an inverse relationship with the quantitative indicator and its performance at a high level. With its implementation at medium and low levels revealed a direct relationship. As the test rate deteriorates, the number of quality passes decreases and the average and low quality performance increases.

With a hit in a tactical attack there is an inverse correlation with the quantitative indicator and qualitative actions and actions at the average level. With the performance of a low-level strike, a direct dependence of the low level is revealed. This indicates an increase in quantitative and qualitative indicators in the performance of tactical strikes with the improvement of test performance data and an increase in low-quality strikes with its deterioration.

With a strike in a strength attack, the Bondarevsky's test has a slight inverse correlation with all indicators.

Table 1. Indicators of static balance of athletes in beach volleyball before and after the experiment $(n=20)$

\begin{tabular}{|c|c|c|c|c|c|c|c|c|}
\hline \multirow{2}{*}{$\mathbf{N}$} & \multirow{2}{*}{ Test } & \multicolumn{2}{|c|}{ To the experiment } & \multicolumn{2}{|c|}{ After the experiment } & \multirow{2}{*}{$\Delta \mathbf{x}$} & \multirow{2}{*}{$\mathbf{t}$} & \multirow{2}{*}{$\mathbf{p}$} \\
\hline & & $\overline{\mathrm{X}}$ & $\mathbf{S}$ & $\overline{\mathrm{X}}$ & $S$ & & & \\
\hline 1. & Bondarevsky & 8.89 & 1.22 & 7.72 & 1.23 & 2.02 & 3.08 & $p<0.05$ \\
\hline 2. & Romberg & 16.68 & 10.29 & 29.92 & 26.07 & 2.02 & 2.11 & $p<0.05$ \\
\hline 3. & Yarotsky & 21.30 & 6.97 & 36.32 & 19.11 & 2.02 & 3.30 & $\mathrm{p}<0.05$ \\
\hline
\end{tabular}

Table 2. Influence of the level of static balance on the indicators of competitive activity of athletes aged $17-21(n=20)$

\begin{tabular}{|c|c|c|c|c|c|c|c|c|c|c|c|c|}
\hline $\begin{array}{l}\text { Tests / } \\
\text { indicators } \\
\text { of game } \\
\text { technique }\end{array}$ & 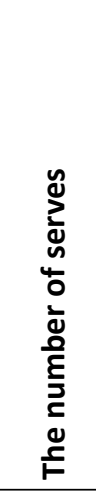 & 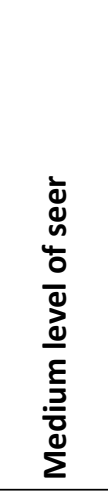 & 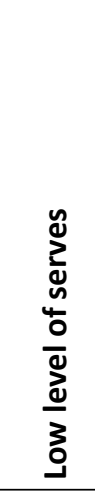 & 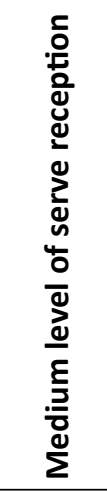 & 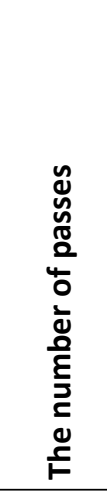 & 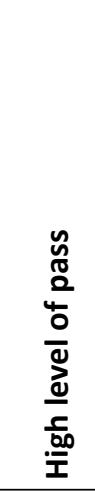 & 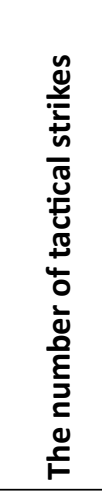 & 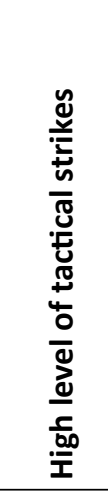 & 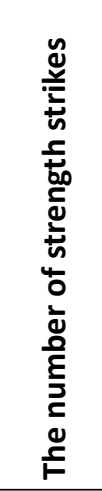 & 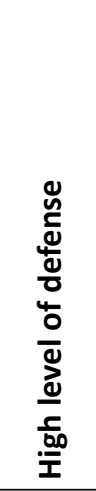 & 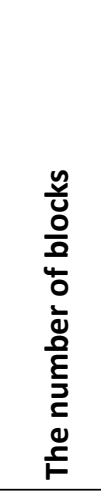 & 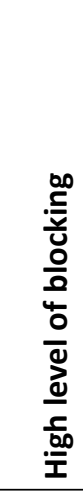 \\
\hline \multirow[t]{2}{*}{ Tests } & \multicolumn{12}{|c|}{ Correlation coefficients between indicators } \\
\hline & \multicolumn{12}{|c|}{ To the experiment } \\
\hline Bondarevsky & -0.55 & -0.28 & 0.19 & 0.49 & -0.24 & -0.45 & -0.23 & -0.39 & -0.26 & 0.17 & -0.36 & -0.21 \\
\hline Romberg & -0.27 & 0.09 & -0.25 & 0.22 & -0.24 & -0.36 & -0.02 & -0.20 & -0.31 & 0.12 & -0.17 & -0.14 \\
\hline \multirow[t]{2}{*}{ Yarotsky } & -0.35 & -0.11 & -0.75 & -0.37 & -0.44 & -0.54 & -0.21 & -0.52 & -0.19 & -0.10 & -0.28 & -0.30 \\
\hline & \multicolumn{12}{|c|}{ After the experiment } \\
\hline Bondarevsky & -0.57 & -0.55 & -0.35 & 0.66 & -0.19 & -0.39 & -0.36 & -0.45 & -0.1 & -0.35 & -0.01 & -0.05 \\
\hline Romberg & -0.34 & 0.01 & -0.47 & 0.28 & -0.26 & -0.35 & -0.02 & -0.23 & -0.33 & 0.03 & -0.2 & -0.19 \\
\hline Yarotsky & -0.39 & -0.2 & -0.35 & 0.49 & -0.38 & -0.54 & -0.2 & -0.42 & -0.02 & -0.07 & -0.29 & -0.36 \\
\hline
\end{tabular}

Note: reliability at $\alpha=0,444$ 
The inverse correlation of increased significance with the majority of indicators is observed with the game in defense in Bondarevsky's tests. With a low level of performance, the coefficient is negligible. As the test rate improves, the quality of the defense improves. With blocking indicators, the Bondarevsky's test does not show significant correlations with any of the indicators.

The Romberg test with the most-serve technique shows a negative correlation coefficient. With the indicator of the average level of performance of the supply of significant dependencies are not detected. As the Romberg test rate increases, the number of serves performed and their performance at a low level decreases.

With the reception of the serve there is a direct correlation between the test at the average level with the average level of performance. As the test rate improves, the number of technical actions performed at the average level increases.

With the pass for the strike, we observe the inverse dependence of the average level with the quantitative indicator of its performance and the indicator of its performance at a high level. The indicator of low quality of performance has a direct correlation dependence of the average level. As the test rate improves, the transmission rate decreases in both cases.

No significant correlations were found with other technical actions. Yarotsky's test with technical action of giving with the majority of indicators reveals inverse correlation dependence. As the test rate improves, the level of serve performance increases and the rate of serve performance deteriorates.

With the rate of serve reception, the test shows a direct correlation between the average level and its performance at the average level. The improvement of the test rate is accompanied by the performance of technical action at a level not lower than average.

There is a complex relationship with the serve to strike in the attack. With a quantitative indicator and its performance indicator at a high level, there is an inverse dependence of the average level. As the sample rate improves, the quantity and quality of the serve deteriorates.

The following correlation dependence is revealed with hits in an attack: with a tactical hit, a high level of its execution it is reversed, and with a force hit with a low level of its execution it is straight and of medium level. That is, with the improvement of the sample rate, the quality of execution of both tactical and force strikes decreases. This may be explained by the presence of a directly opposite dependence of the stability of vestibular reactions with the quality of the hits in the attack, which is the exact opposite of our previous hypothesis.

Yarotsky's test does not reveal significant dependencies with the game in defense. With the technique of blocking there is an inverse correlation with all indicators, quantitative, high, medium and low levels of its performance. Taking into account the specifics of the test (constant rotation of the head), it can be noted that in the game there is no need for constant long-term (for more than $20 \mathrm{~s}$ ) irritation of the vestibular centers. This leads to overstrain of the vestibular static balance system and does not meet the needs of the game. To a greater extent, shortterm stimuli (up to 2-3 s) of the system are required in the episodes of the game, which is reflected in the presence of positive dependences in samples with a less pronounced effect of irritation of the vestibular centers.

The obtained results of the study indicate the difference in samples with different nature of the work. In particular, Yarotsky's test characterizes somewhat other qualities of vestibular stability, which are not used during competitive activities in beach volleyball, and the test significantly outweighs the game factors of irritation of athletes' vestibular centers. However, the planned exercise in these conditions (significant excess of the allowable time) during sports training can have a positive effect as an increase in statokinetic (vestibular) balance and improve the agility of beach volleyball athletes in the future.

Bondarevsky's test is directly related to the quality of tactical strikes, high-level performance in defense and the number of the serves not below the average. Romberg's test leads to the improvement of the quality of serves by reducing the number of serves at a low level. However, it has a negative relationship with the quantitative and qualitative indicators of hits in a forceful attack.

Overstrain of the vestibular centers can negatively affect the quality of the hits in the attack and blocking. Therefore, the process of sports training should include restorative microcycles, during which the process of adaptation to previous vestibular loads is fully completed.

\section{Discussion}

During our study, the average value of the Yarotsky sample was determined to be $35.8 \mathrm{~s}$. According to Serhienko in co-authorship [8] the scale of assessment of static balance in the sample is $35 \mathrm{~s}$ - excellent, $20 \mathrm{~s}$ good, $16 \mathrm{~s}$ - satisfactory. We found: the assessment well is registered in $35 \%$ of respondents. $65 \%$ of respondents are rated well.

We determined the relationship between the levels of static balance in different tests and the performance of individual elements of the technique of playing beach volleyball in a competitive environment. Bondarevsky's test most predictably corresponds to indicators of efficiency of technical actions. With the improvement of the sample (decrease of the indicator) the quantitative and qualitative indicators of technical actions increase, in particular the serve, the serve reception, the passing, the tactical strike in the attack, the game in the defense. With the elements of the game of speed and force character (the hit in the attack of force and blocking character, the leading physical quality is jumping ability), the dependence of the stability of vestibular reactions is not observed. Romberg's test with not all elements of technology is predictable. In particular, there is a mismatch in the serve and the pass due to the overvoltage of the vestibular centers. The discrepancy between the expected and existing dependence of Yarotsky's test with the quality of technical actions was revealed. This indicates the 
presence of overstrain of the vestibular centers, which has no immediate effect, but may have a delayed effect. The time of Yarotsky's test significantly exceeds the vestibular loads that an athlete experiences during competitive beach volleyball activities. This issue requires additional research. All these factors make it possible to determine the areas of coordination skills and dexterity on the basis of which it is necessary to build the process of further sports improvement of beach volleyball athletes.

The study confirmed the data of Tymoshchenko [5], Pelzer et al. [6], Wergin et al. [7], Kostiukevich [29] on the management of technical and tactical activities and sports training, strength and endurance of leg muscles. The data of Balasas et al. [31] on the use of loads for the development of coordination, agility, vestibular stability, strength and endurance of the leg muscles are also confirmed. The opinions of Shankulov et al. [32] agree on the relationship between efficiency and quality of performance of certain technical actions with special physical qualities, including strength and agility (accuracy and timeliness) in volleyball. Solovey and Hunchenko [8] share the same opinion regarding beach volleyball. In the study the data of Platonov [3], Kostiukevych [29], Doroshenko [30] as for the basis for competitive activities in complex coordination sports, in particular - the physical fitness of athletes; and also the data of Kostyukov [22], Hemberg et al. [23] and Koliago [36] on the dependence of the effectiveness of competitive beach volleyball activities on the rational construction of the process of sports training, were developed.

The data of Horchaniuk [18, 19] concerning the uneven distribution of efforts of unskilled beach volleyball athletes during movements and jumps have been supplemented. When performing jumps, the horizontal position of the foot is not provided, which does not correspond to the model characteristics of jumps and movements of highly qualified athletes? All this leads to the athlete being delayed in the place of repulsion during the jump when changing the direction of the ball. This is due to insufficient special physical training of athletes, in particular insufficient development of agility and vestibular stability.

The data of Castro et al. [37], Papadimitriu et al. [38], Jaworska et al. [40], Wnorowski et al. [41] on the dependence of the effectiveness of offensive actions on the speed of attack, the quality of transmission that precedes them, and the level of development of special physical qualities of athletes received further development.

\section{Highlights}

The study was performed in accordance with the thematic research plan of the Dnipro State Academy of Physical Culture and Sports (Ukraine) for 2016-2020 on the topic "Theoretical and methodological foundations of planning and control in sports games in the process of long-term improvement", state registration number $0116 \mathrm{U} 003012$.

\section{Conclusions}

The proposed methodological approach significantly affects the performance of competitive activities and is directly related to the quality of tactical strikes, highlevel performance in defense and the number of serves. The process of sports training should include restorative microcycles, during which the process of adaptation to previous vestibular loads is fully completed.

\section{Conflict of interests}

The authors state that there is no conflict of interests.

\section{References}

1. Platonov VN. The system of training athletes in Olympic sports. Kiev: Olympic Literature; 2004. (In Russian).

2. Falch HN, Raedergard HG, van den Tillaar R. Effect of Different Physical Training Forms on Change of Direction Ability: a Systematic Review and Meta-analysis. Sports Medicine-Open. 2019;5(1). https://doi.org/10.1186/s40798-019-0223-y

3. Platonov VN. The system of training athletes in Olympic sports. General theory and its practical applications. Kiev: Olympic Literature; 2015. (In Russian).

4. Solovey O, Gunchenko V, leading physical qualities as a factor influencing the result competitive activities in beach volleyball. Sportivnij visnik Pridniprov'ia, 2019;1:85-94. https://doi.org/10.32540/2071-1476-2019-4-085

5. Tymoshchenko OV. The value of strength and accuracy of movements for competitive activities in various sports. Naukovyy chasopys NPU im. M.P. Drahomanova. 2016; 1(70:186-190. (In Ukrainian).

6. Pelzer T, Schmidt M, Jaitner T, Pfeiffer M. External training load and the effects on training response following three different training sessions in young elite beach volleyball players. International Journal of Sports Science \& Coaching. 2020;15(5-6):717-727. https://doi.org/10.1177/1747954120940488

7. Wergin VV, Juergen, Gropel P, Mesagno C. Investigating cumulative effects of pre-performance routine interventions in beach volleyball serving. Plos One. 2020;15(1). https://doi.org/10.1371/journal.pone.0228012

8. Solovey OM, Hunchenko VV. Analysis of the effectiveness of the results of competitive activities in beach volleyball. Sportivnij visnik Pridniprov'ia, 2018;3: 126 - 130. (In Ukrainian).

9. Sergiienko L, Chekmar'ova N. Human sensorimotor coordination: terminological concept and classification. Moloda sportivna nauka Ukraini, 2007;11:292 - 293. (In Ukrainian).

10.Serhiyenko LP, Chekmar'ova NH, Khadzhynov VA. Psychomotor: control and evaluation of development. Kharkiv. Education, training, sports; 2012. (In Ukrainian).

11.Afanasyev S, Burdayev K. Formation of the vertical stability of the body of junior schoolchildren with hearing impairments in the process of physical education. Journal of Education, Health and Sport 2017;7(6):1169-1178. https://doi.org/10.5281/zenodo. 1252452

12.Glaznikov LA, Blaginin AA, Sorokina LA, Buynov LG, Syroezhkin FA, Nigmedzianov RA, et al. Efficiency of Electrical Tranquilization of the Central Nervous System 
in Combination with Vestibular Training to Improve the Statokinetic Stability. Hum Physiol, 2018;44:753-8. https://doi.org/10.1134/S0362119718070034

13.Hunchenko VV. The effectiveness of attacking blows as a determining factor in competitive activities in beach volleyball. Sportivnij visnik Pridniprov'ia, 2019; 1: 3-12. (In Ukrainian).

14.Natali S, Ferioli D, La Torre A, Bonato M. Physical and technical demands of elite beach volleyball according to playing position and gender. Journal of Sports Medicine and Physical Fitness. 2019;59(1):6-9. https://doi.org/10.23736/s0022-4707.17.07972-5

15.Prieur J, Le Du G, Stomp M, Barbu S, Blois-Heulin C. Human laterality for manipulation and gestural communication: A study of beach-volleyball players during the Olympic Games. Laterality. 2020;25(2):229-254. https://doi.org/10.1080/1357650x.2019.1648485

16.Kozina ZHL, Pohoryelova AO, Polishchuk SB. Methods of training volleyball players aged 16-17 with an emphasis on the development of psychophysiological capabilities. Problemi formuvannia $j$ udoskonalennia sportivnoi majsternosti, 2014;1: 83 - 89. (In Ukrainian).

17.Zamporri J, Aguinaldo A. The Effects of a Compression Garment on Lower Body Kinematics and Kinetics During a Drop Vertical Jump in Female Collegiate Athletes. Orthopaedic Journal of Sports Medicine. 2018;6(8). https://doi.org/10.1177/2325967118789955

18. Horchanyuk YuA. Technical training of athletes in beach volleyball based on biomechanical models of jumps and movements. [dissertation]. Kharkiv; 2004. (In Ukrainian).

19. Horchanyuk Yu.A. Competitive loads in beach volleyball. International Scientific and Methodological Conference, February 27-28, 2002. Belgorod; 2002. P. 143-145. (In Russian).

20.Lisians'kij VK, Pokholenchuk IuT, Tomashevs'kij VA, Operajlo SI, Doroshenko EIu. Beach volleyball. Kiev; 2002. (In Ukrainian).

21.Kostyukov VV, Nyrka VV. Beach volleyball (pedagogical, biomedical and psychological support for the training of athletes). Moscow: Volleyball Federation; 2011. (In Russian).

22.Kostyukov VV. Beach volleyball (training, technique, tactics). Moscow: Soviet sport; 2005. (In Russian).

23.Khemberg S, Papageorgiu A. Beach volleyball. Moscow: Terra-Sport; 2004. (In Russian).

24.Lin K (Kyle). Applying Game Theory to Volleyball Strategy. International Journal of Performance Analysis in Sport, 2014;14:761-74. https://doi.org/10.1080/24748668.2014.11868756

25.Hunchenko VV. Serving efficiency as an important factor of competitive activity in beach volleyball. Fizichna kul'tura, sport ta zdorov'ia nacij; 2018;6(25): 122-128. (In Ukrainian).

26. Giatsis G. The effect of changing the rules on score fluctuation and match duration in the FIVB women's beach volleyball. International Journal of Performance Analysis in Sport, 2003;3:57-64. https://doi.org/10.1080/24748668.2003.11868275

27.Drikos S, Kountouris P, Laios A, Laios Y. Correlates of Team Performance in Volleyball. International Journal of Performance Analysis in Sport, 2009;9:149-56. https://doi.org/10.1080/24748668.2009.11868472

28.Araújo RM, Castro J, Marcelino R, Mesquita IR. Relationship between the Opponent Block and the Hitter in Elite Male
Volleyball. Journal of Quantitative Analysis in Sports, 2010;6. https://doi.org/10.2202/1559-0410.1216

29.Kostiukevich VM. Management of the training process of football players in the annual training cycle. Vinnitsa: Planer; 2006. (In Ukrainian).

30.Doroshenko EIu. Management of technical and tactical activities in team sports games. Zaporozhye: LLC «LIPS» LTD; 2013. (In Ukrainian).

31.Balasas DG, Christoulas K, Stefanidis P, Vamvakoudis E, Bampouras TM. The effect of beach volleyball training on muscle performance of indoor volleyball players. J Sports Med Phys Fitness, 2018;58:1240-6. https://doi.org/10.23736/S0022-4707.17.07162-6

32.Shankulov Y, Andrusyshyn I, Zaurenbekov B, Zhunisbek D, Akhmetkarim M. Planning efficiency of athletic preparations of highly qualified volleyball players in annual macro-cycle. JournalofPhysicalEducationandSport, 2020;20(1):262-266. https://doi.org/10.7752/jpes.2020.01035

33.Tili M, Giatsis G. The height of the men's winners FIVB Beach Volleyball in relation to specialization and court dimensions. International Congress of Physical Education \& Sport, 2011;6:504-10. https://doi.org/10.4100/jhse.2011.63.04

34.Silva M, Lacerda D, João PV. Game-Related Volleyball Skills that Influence Victory. Journal of Human Kinetics, 2014;41:173-9. https://doi.org/10.2478/hukin-2014-0045

35.Medeiros AIA, Palao JM, Marcelino R, Mesquita I. Revisão sistemática sobre a performance desportiva no voleibol de praia a partir da análise do jogo. Rev Bras Cineantropom Desempenho Hum, 2014;16:698. https://doi.org/10.5007/1980-0037.2014v16n6p698

36.Koliago PV. Dynamics of the level of physical fitness in the annual training of athletes in beach volleyball. Fizicheskaia kul'tura $i$ sport - nauka i praktika, 2009;4:14-17. (In Russian).

37.Castro J, Souza A, Mesquita I. Attack Efficacy in Volleyball: Elite Male Teams. Percept Mot Skills, 2011;113:395-408. https://doi.org/10.2466/05.25.PMS.113.5.395-408

38.Papadimitriou K, Pashali E, Sermaki I, Mellas S, Papas M. The effect of the opponents' serve on the offensive actions of Greek setters in volleyball games. International Journal of Performance Analysis in Sport, 2004;4:23-33. https://doi.org/10.1080/24748668.2004.11868288

39. Sweeney EA, Wilson JC, Potter MN, Dahab KS, Denay KL, Howell DR. Symptom profiles and postural control after concussion in female artistic athletes. Brain Injury, 2020;34(7):928-933. https://doi.org/10.1080/02699052.2020.1763464

40.Jaworska J, Micielska K, Kozłowska M, Wnorowski K, Skrobecki J, Radzimiński L, et al. A 2-Week Specific Volleyball Training Supported by the Whole Body Cryostimulation Protocol Induced an Increase of Growth Factors and Counteracted Deterioration of Physical Performance. Front Physiol, 2018;9:1711. https://doi.org/10.3389/fphys.2018.01711

41.Wnorowski K, Cieminski K. Volleyball players' somatic composition in the light of sports results at 2014 FIVB Volleyball Men's World Championship. Baltic Journal of Health and Physical Activity, 2016;8(4):24-31. https://doi.org/10.29359/bjhpa.08.4.03 


\section{Information about the authors:}

Oleksandr Solovey; (Corresponding author); https://orcid.org/0000-0001-8480-2323; 1Soloveyaleksandr@gmail.com; Department of Sports Games; Prydniprovsk State Academy of Physical Culture and Sports; Naberezhna Pobedy str., 10, Dnieper, 49010, Kiev, Ukraine.

Valeriy Hunchenko; https://orcid.org/0000-0002-1986-1068; altair66v@gmail.com; Department of Sports Games; Prydniprovsk State Academy of Physical Culture and Sports; Naberezhna Pobedy str., 10, Dnieper, 49010, Kiev, Ukraine.

Dmytro Solovey; https://orcid.org/0000-0001-8105-2061; 1Soloveydmitriy@gmail.com; Department of Sports Games; Prydniprovsk State Academy of Physical Culture and Sports; Naberezhna Pobedy str., 10, Dnieper, 49010, Kiev, Ukraine.

Krzysztof Wnorowski; https://orcid.org/0000-0001-5505-7985; krzysztof.wnorowski@awf.gda.pl; Department of Sports, Gdansk University of Physical Education and Sport,; Gdansk, Poland.

Cite this article as:

Solovey O, Hunchenko V, Solovey D, Wnorowski K. Influence of static balances level on competitive performance indicators of athletes 17-21 years old in beach volleyball. Physical Education of Students, 2020;24(6):332-339. https://doi.org/10.15561/20755279.2020.0605

This is an Open Access article distributed under the terms of the Creative Commons Attribution License, which permits unrestricted use, distribution, and reproduction in any medium, provided the original work is properly cited http://creativecommons.org/licenses/by/4.0/deed.en

Received: 18.10 .2020

Accepted: 02.12.2020; Published: 30.12.2020 